\title{
Were Adolescent Sexual Offenders Children with Sexual Behavior Problems?
}

\author{
David L. Burton ${ }^{1}$
}

This article compares responses of three groups of incarcerated adolescents who admitted to sexual offending in an anonymous survey project on measures of trauma, sexual offending, the relationship between trauma and perpetration, and adjudication status. The first group admitted to sexual offending before the age of 12 only $(\mathrm{n}=48)$, the second after the age of 12 only $(\mathrm{n}=130)$, and the third before and after the age of $12(\mathrm{n}=65)$. More than $46 \%$ of the sexually aggressive adolescents began their deviant behaviors before the age of 12. Level and complexity of perpetration acts were more severe for the continuous offenders than for the other groups. Victimization and perpetration were significantly correlated for all three groups. This study supports a social learning hypothesis for the development of sexual offending by adolescents. Implications for research and clinical practice are drawn.

KEY WORDS: adolescent sexual aggression; social learning theory; victimization.

\section{INTRODUCTION}

Children with sexual behavior problems generally exhibit a large range of sexually and physically aggressive behaviors and typically have severe sexual victimization histories (Burton, 1999; Burton, Nesmith, \& Badten, 1997; Johnson, 1988). Their parents and siblings are frequently survivors of sexual abuse and often suffer substance abuse and/or pathology of other sorts (Friedrich \& Luecke, 1988; Johnson \& Berry, 1989; Pithers, Gray, Busconi, \& Houchens, 1998).

Understanding children's behavior in order to assist in its change is difficult for many reasons, including the great variety of their behavioral patterns and background histories (Pithers \& Gray, 1997). Theoretically based treatment has been

${ }^{1}$ School of Social Work, The University of Michigan, 3734 Social Work Building, University of Michigan, Ann Arbor, Michigan 48109-1280; e-mail address: burtond@umich.edu. 
evaluated in two recent National Institute of Child Abuse and Neglect studies, both of which offer descriptive and theoretical information about the children, their families, and treatment (Bonner, Walker, \& Berliner, 1994; Gray \& Pithers, 1994). Theory has been discussed with reference to treatment and to offer possible explanations of etiology (Cunningham \& MacFarlane, 1991; Gil \& Johnson, 1994). One empirical theoretical exploration using social learning theory has been provided as a further step in this process (Burton et al., 1997).

If social learning theory is a sound theoretical position for both etiological explanation and treatment of these behavioral challenges, several questions must be answered. What are the differences in trauma background, or learning history, for all of the many victims of sexual abuse who do not act out sexually versus the few who do? Are there differences in the frequency, duration, relationship, and/or gender of the abuser of the children? Are there differences in emotional response, recall, current stress symptoms, and age of the victim at the time of abuse or in other variables? What are the thoughts and understandings about sexual behavior (Burton, 1999), intimacy, boundaries, morals, and relationships with the victims of the children who do act out? What exactly can we understand about the familial environment and how is problematic sexual behavior learned, passed on, and reinforced? How do we explain the roughly $30 \%$ of boys who act out sexually for whom we cannot find history of sexual victimization? W. Friedrich (personal communication, Oct. 16, 1997) offers exposure to sex, sexual video exposure, and family nudity as possibilities for this last question, but more research is needed to support or verify these and other possible explanations.

This study is primarily concerned with the progression and development of sexual offending, a potentially progressive public health hazard (Freeman-Longo \& Blanchard, 1997). Do children with sexual behavior problems become more serious and harmful adolescent and/or adult offenders? In writing about adults, Abel, Osborne, and Twigg (1993) report that "histories of 1,025 paraphiliacs revealed that $446(42.3 \%)$ reported the onset of their paraphilia prior to age 18." In addition, " . . a high percentage of individuals reported the onset of the paraphilic behavior interest by age 17" (pp. 108-109). In a study of adolescent sexual offenders, Hunter (1994) reported that sexual offending was progressive over time. In adding childhood behaviors to the picture of development of some offenders, new questions arise. Do some adult offenders start acting sexually inappropriately as children? What is the prognosis for children who have sexually inappropriate behaviors? Do they progress through adolescent offending to adult offending or stop somewhere along the way?

Children who are known to have sexually inappropriate behaviors before age 6 have been found to have more sexual victimization, are more likely to see their inappropriate behaviors as "normal," and have more victims (Burton et al., 1997). Are there similar differences among adolescent or adult offenders who manifest sexual behavior problems as children? If children with sexual behavior problems do progress to adolescents with more severe behaviors and then possibly to adult 
sexual offenders, the need for early identification and treatment for these youth is clear. Are there children who do not progress beyond acting out as children? If so what helps them stop?

Sexual abuse may help explain some of the etiological questions of sexual offending. For children with sexual behavior problems under the age of 12, rates of having been sexually victimized range from 65 to 100\% (Burton et al., 1997; Friedrich \& Luecke, 1988; Gil \& Johnson, 1994; Hunter, 1994). Research has repeatedly found sexual victimization in the histories of sexually aggressive adolescents at rates of 50-65\% (Becker, Cunningham-Rathner, \& Kaplan, 1987; Burgess, Hartman, McCormack, \& Grant, 1995; Davis \& Leitenberg, 1987; Vizard, Monck, $\&$ Misch, 1995). Based on these findings and on clinical observation and efforts, the primary etiological theories of sexual offending focus on a social learning hypothesis. Howells (1981) called his conceptualization a "sexual learning theory" based on Bandura and Walters' (1969) social learning theory. Burton et al. (1997) found that using Bandura's social learning theory, which is based on modeling, a number of factors, including whether or not a child was sexually abused and the number of perpetrators he or she was abused by, significantly accounted for the number of victims the child had sexually perpetrated.

Doumas, Margolin, and John (1994) explored the same theory in an empirical study of three generations of families in which offending was transmitted across generations. They investigated witnessing of abuse, which was able significantly to predict offending across generations. Garland and Dougher (1990) thoroughly investigated the literature, up to that date, on the abused/abuser hypothesis of child sexual abuse. They concluded that "the available evidence indicates that sexual behavior between an adult and child or adolescent is neither a necessary nor a sufficient cause of similar behavior in the child or adolescent. ... If sexual behavior with an adult is related to an ... adolescent's repeating the behavior ... it is related only in the context of other, interacting variables" (Garland \& Dougher, p. 505). They point out several variables that may contribute to the development of an offender including the severity of the victimization, the age at which one is sexually victimized, the use of force during the victimization, the gender of the perpetrator, the duration and frequency of the abuse, the number of perpetrators, and the age difference between the victim and the offender.

The current study focuses upon describing incarcerated youth in three groups in terms of sexual perpetration and then upon the level and complexity of the offender's victimization with four analyses across the groups. The first group admitted to committing sexually aggressive behaviors since childhood. A second group admitted to committing sexually aggressive acts only after the age of 12 and a third reported that they had committed sexually aggressive acts before, but not after, the age of 12 .

The first analysis compares the level and the complexity of sexually aggressive acts and behavioral patterns across the three groups. The second analysis explores differences in adjudication status across the three groups. The third questions the 
differences in sexual trauma experiences across the three groups. The final analysis considers the relationship between victimization and perpetration across the three groups. The hypothesis for these analyses are that the first group, the continuous sexual offenders, will have greater level and complexity of acts, are more likely to be adjudicated as sexual offenders, and will have more experiences of trauma and a stronger relationship between victimization and perpetration than the other groups.

\section{METHOD}

A public residential facility, a private residential facility, and a community/ halfway house, all of which treat adolescent male sexual offenders in Michigan, participated in an anonymous cross-sectional survey project of 471 youths. Among these were 122 adjudicated for sexual offending (9 of whom denied any sex offenses). There were also another 150 youth adjudicated for nonsexual crimes who admitted to sexual offending in their lifetime. Seventy-eight youth admitted to penetrative acts of sexual offending as their most severe act, 22 admitted to fondling as their most severe act, and 50 admitted to noncontact acts as their most severe (e.g., exhibitionism).

The 263 youths, who admitted sexual offenses, were divided into three groups regardless of adjudication for sexual offenses or other crimes: those who reported sexual offenses as children that continued into their teen years $(n=65)$ (continuous offenders), those who admitted to such offenses starting at 12 years or older $(n=130)$ (teen offenders), and those who admitted to sexual behavior problems only before the age of 12 and not after that $(n=48)$ (early offenders). The age of 12 was chosen as 12.34 years is the reported beginning of puberty for youth in the United States (Roche, Wellens, Attie, \& Siervogel, 1995).

There were no significant differences in current age or ethnic background of the three groups. The average age for the youth was 16.9 years $(\mathrm{SD}=1.63$ years) with a range from 12 to 22. Their ethnic background was $40 \%$ African American, 40\% Euro American, 6\% Hispanic, 9\% Native American, and 5\% other ethnicities. On average they reported being in the late eighth grade.

\section{Recruitment and Selection}

This was a purposive convenience sample. In two of the institutions, all of the boys were given the opportunity to participate if they had their clinical teams' approval. (Only 14 youth were not given approval due to extremely difficult behavior management or clinical concerns.) In the third institution, parental consent was also required. There was no way to determine differences between those who agreed, or who were approved and agreed, and those who were not allowed, or did not wish, to participate. In each institution, the administration, clinical leadership, clinical team, and on-line staff were consulted and asked for approval for each 
boy's participation. An on-site staff liaison facilitated the process of group administration of the surveys. A staff member was available for any youth feeling the need to process the material in the survey $(n=3)$. The youth were given a pizza party with soda pop for participation.

\section{Materials}

The instruments reported here were among several used for a larger study investigating effects of childhood trauma on sexual offending and criminal behavior with several mediating and moderating factors for both sexual offenders and nonsexual offending juvenile delinquents. After changes based on tests for face validity and completion of several pilot tests of the entire package, demographic data were collected along with the following instruments:

A modified version of the Sexual Abuse Exposure Questionnaire (SAEQ) (Ryan, Rodriguez, Rowan, \& Foy, 1992) was used to assess the type(s) of sexual abuse experienced and other dimensions of victimization. Statistical reliability for this instrument was tested with Cronbach's $\alpha$, which was .86 , with an 8 week test-retest agreement, for a small sample, of $79 \%$.

The Childhood Trauma Questionnaire (CTQ; Bernstein \& Fink, 1993) is a 37-item scale that provides brief and relatively noninvasive screening of traumatic experiences in childhood. All of the subscales were statistically reliable in this study. The subscales include physical abuse $(\alpha=.81)$, emotional abuse $(\alpha=.83)$, sexual abuse $(\alpha=.82)$, and physical $(\alpha=.70)$ and emotional $(\alpha=.92)$ neglect.

The Self Report Sexual Aggression Scale (SERSAS) is an inventory created for the present study (Burton \& Fleming, 1998). The scale paralleled the modified SAEQ, but measured sexually aggressive behaviors over the life span. Questions about several sexual acts were all prefaced with "Have you ever conned or forced someone to ... ?" During administration, youth were told that we were interested only in descriptions of sexually inappropriate behaviors. Reliability for this instrument was tested with Cronbach's $\alpha$, which was good at .87 , with an 8 week test-retest agreement, for a small sample, of $96 \%$.

\section{RESULTS}

\section{Differences in the Levels and Complexity of Sexually Aggressive Acts and Behavioral Patterns Across the Three Groups}

All youth were asked if they had "ever conned or forced anyone" to do any of several sexual behaviors ranging from fondling to penetration with objects, digits, or penis. They were also asked at what age they first began each sexually inappropriate behavior. Determining which sexual behaviors are more severe and therefore 
Table I. Trichotomy of Acts

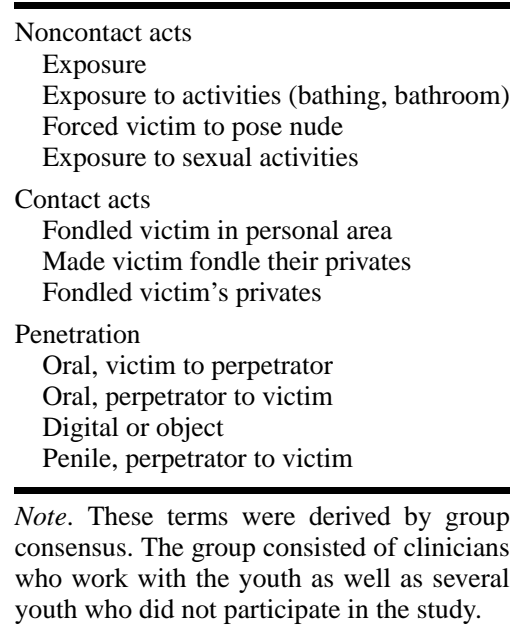

take priority over others may not be possible unless one considers duration, frequency, modus operandi, age of victim, and other characteristics of the offending behavior. For this study, the acts reported by all youth admitting to sexually aggressive acts were categorized into three mutually exclusive levels which indicate the most severe act committed: (a) noncontact; (b) contact, but not penetrative; and (c) penetrative acts. These are further described in Table I. Group membership status was significantly associated with level of act $\left[\chi^{2}(4, N=242)=23.82\right.$, $p<.001]$. A larger percentage of the continuous sexual offenders admitted to sexually penetrative acts than the early or teen offenders. The early offenders reported the lowest levels of perpetration.

The youth were given a score that sums the values across each level of act to capture complexity, seriousness and progression of the acts. Scores were assigned for each possible report, increasing with the severity and complexity of the act(s): (1) exhibitionism only, (2) fondling only, (3) fondling and exhibitionism, (4) penetration only, (5) exhibitionism and penetration, (6) fondling and penetration, and (7) all three acts. Group membership was significantly associated with the severity and complexity of the acts reported, with larger percentages of the continuous offenders reporting more of the types of severe and complex acts than the other groups $\left[\chi^{2}(12, N=242)=42.62, p<.001\right]$. The early offenders reported the lowest levels of perpetration.

There are significant differences in the behavioral patterns across groups $\left[\chi^{2}(6, N=174)=17.28, p<.01\right]$. In each of the three groups a large number of youth committed penetrative acts. Continuous offenders were more likely to have committed all three acts. Early offenders were more likely to have committed penetration solely and the teen offenders were more well distributed across the possible 
single and combination acts. Looking exclusively at the penetrators' behaviors across the three groups, $88 \%$ of the continuous offenders who committed a penetrative act also committed exhibitionism, 91\% also committed fondling, and $80 \%$ committed all three acts. Seventy-eight percent of the teen offenders who committed a penetrative act also committed exhibitionism, $75 \%$ also committed fondling, and $65 \%$ committed all three acts. While only $60 \%$ of the early offenders who committed a penetrative act also committed exhibitionism, $78 \%$ also committed fondling, and $60 \%$ committed all three acts.

\section{Adjudication Status Across the Three Groups}

Group membership was significantly, although weakly, associated with adjudication status (for sexual offending versus other crimes) $\left[\chi^{2}(2, N=174)=6.4\right.$, $p<.05]$. Adjudicated offenders were more likely to have been continuous offenders while youth adjudicated for other crimes were more likely to report themselves as early offenders. Youth who were in the teen offending group were about as equally likely to be adjudicated for sexual offenses as for other crimes.

\section{Differences in Trauma Across the Three Groups}

The CTQ short-form offers several subscales. These scales were calculated for all three groups. ANOVAs were used to compare the groups. Significant differences between groups were found in sexual abuse $[F(2,232)=6.04, p<.005]$, emotional abuse $[F(2,240)=4.92, p<.01]$, and total scores $[F(2,240)=3.79$, $p<.05]$. The difference in the total score stems almost totally from the differences in the preceding two subscales. In posthoc Scheffe analyses, the significant differences between the group means on the three scales were between the continuous offenders and the teen offenders. Group means, presented in Table II, clearly illustrate that while the early offenders had high means on these three scales, the continuous offenders had the highest mean and the teen offenders the lowest. According to the preliminary norms reported for the instrument, these youth scored higher than most of the populations thus far evaluated.

The victimization histories were collapsed into three levels of noncontact abuse, contact abuse, and penetrating acts of abuse, to assess the level of sexual

Table II. CTQ Group Means on Significant Scales

\begin{tabular}{lccc}
\hline & Continuous offenders & Early offenders & Teen offenders \\
\hline Sexual Abuse Scale & 11.81 & 11.17 & 9.16 \\
Emotional Abuse Scale & 15.24 & 13.54 & 12.78 \\
Total CTQ Scale & 91.52 & 86.88 & 81.08 \\
\hline
\end{tabular}


victimization. Level of reported victimization and group membership were not significantly associated $\left[\chi^{2}(4, N=199)=4.04, p>.40\right]$. Although $82 \%$ of the continuous offenders reported having been penetrated during their victimization as a child, $73 \%$ of the early offenders and $73 \%$ of the teen offenders reported penetration during victimization as children. These were summed into a 0-7 scale. Scores were assigned for each possible report of victimization, increasing with severity and complexity of act(s): (1) exhibitionism only, (2) fondling only, (3) fondling and exhibitionism, (4) penetration only, (5) exhibitionism and penetration, (6) fondling and penetration, and (7) and all three acts. Complexity of victimization and group membership were not significantly related $\left[\chi^{2}(14, N=242)=18.09, p>.20\right]$. While this summed score does not capture the same elements as the CTQ subscales, they are closely related for the entire sample $(r=.605, p<.001)$.

\section{Relationships Between Levels of Victimization and Perpetration Across the Three Groups}

Level of victimization and the level of perpetration were significantly correlated $(r=.372, p<.001)$ for the entire sample. The $0-7$ summed scores for sexual victimization and sexual perpetration significantly correlate $(r=.501, p<.001)$ for the entire sample.

For the overall sample, regressing all of the CTQ subscales and the 0-7 scale that sums the victimization complexity onto the complexity of perpetration indicates that only the sexual abuse and the victimization complexity were significant predictors of the complexity of sexual perpetration $[F(6,252)=25.12$, $\left.p<001, R^{2}=.380\right]$. A parsimonious model dropping all but the sexual abuse subscale and the victimization summed score results in an $F(2,252)=74.5(p<.001$, $\left.R^{2}=.374\right)$, which seems a better choice. To evaluate possible differences in relationship between victimization and perpetration across groups, multivariate regression was utilized. Using these analyses with two dummy coded variables for the three groups (a) to predict perpetration level from victimization level and (b) to predict perpetration complexity from victimization complexity, no interactions effects were significant at the .05 level. The relationship between victimization and perpetration level or victimization and perpetration complexity was not statistically different across the three groups.

\section{DISCUSSION}

Similar to Able and co-workers' (1993) retrospective report on the backgrounds of adult sexual offenders, about $45 \%$ of the adjudicated offending adolescents admitted to sexual offending prior to the age of 12 and $47 \%$ of the entire sample reported having been children with sexual behavior problems. 
Youth who were in the continuous offender group had higher levels and more complex patterns of perpetration. The early offenders had the lowest level and the lowest complexity of perpetration. In part these polarized findings may be related to power dynamics, opportunities, access, and knowledge which might all increase with age. Additionally biopsychosocial pressures might increase with teen offenders (e.g., hormones, sexual identity and trauma resolution, and societal and group pressures). Finally, the continuous offenders may have had a longer time to learn and reinforce offending skills and to commit more severe and complex crimes than either of the other two groups.

Youth who commit penetrative acts tend to commit fondling and exposure first. However, not all youth that fondle progress to penetration, but most who penetrate have exposed and then fondled prior to acts of penetration. In addition, there are differences in progression patterns or in the level of progression (it is not possible to tell which without a longitudinal study) across the three groups. Progression to more severe acts is generally assumed by treatment providers and has been tentatively found in other areas of violence (Widom, 1989).

The high levels of trauma indicated for the youth are not surprising from a clinical perspective. All the groups scored high on most of the scales compared to normative samples. The continuous offenders had higher mean scores on the sexual abuse, emotional abuse and overall scales than either of the other groups. The second highest scores were from the early offenders and the lowest scores were from the teen offenders. The continuous offenders had higher trauma and perpetration scores. These findings are similar to those indicated in an earlier study on children who had sexual behavior problems, demonstrating that younger children who acted out sexually had more victimization (Burton et al., 1997).

The seriousness and complexity of the youth's experience of victimization were moderately and significantly correlated to their own perpetration behaviors. Only a small but significant amount of the complexity and level of perpetration could be predicted from the level and complexity of a youth's victimization. The three group regressions did not find any differences in correlation between victimization and perpetration. This may be due to sample size, instrumentation issues, or lack of measuring the multidimensional impact of victimization on offending. This method of analysis misses several of the elements discussed above which are needed for complete statistical tests of this model. Yet the findings of a group who may have stopped forceful sexual behavior, the high and interesting comparative findings of the trauma results and the correlations of complexity and level may help explain some of the elements of the model and lead to further explorations of a social learning basis of adolescent sexual perpetration.

Implications for treatment are several. First many sexually aggressive youth are severely traumatized. This validates the movement in the field toward resolution of that trauma as an important and relevant factor in treating child and adolescent sexual offenders (Burton, Freeman-Longo, \& Fiske, 1999). Sexually offending youth appear more traumatized than nonsexually offending youth but both have 
high scores and many experiences of severe victimization (Burton \& Fleming, 1998). This lends credence to the recommendation that treatment be strongly fortified with trauma resolution techniques.

Given the differences in severity of perpetration behaviors and in differences on at least one measure of trauma, the CTQ, between these groups, are these three groups useful for analysis? The most progressive group, the continuous offenders, report the greatest level and the greatest complexity of perpetration acts. They also report the greatest levels of trauma on the CTQ. However, the modified instrument, the SAEQ, used to assess other differences did not find, at this level of analysis, differences in victimization level or complexity across the three groups. Did the early offender group lie about stopping because of fear of prosecution? If not and these three groups truly exist, several questions about the development of sexual offenders and sexual offending behavior may be raised for future research and treatment. What are the differences between those that stopped and those that did not? Can we use those differences for treatment? What happened to their sexualized behavior? Was it diverted to other criminal behavior? If so, why and how? Longitudinal studies on children with sexual behavior problems are needed. Controlled group design studies on the differences between sexual offenders who receive trauma resolution treatment and those who do not and on dynamic recidivism risk factors for youth are also needed.

This study offers more detail on the relationship between victimization and perpetration than previously supplied and supports a social learning theory perspective for the development of adolescent sexual aggressors. Although limitations include a nonrandom sample and retrospective review, the sample used represented approximately $75 \%$ of all incarcerated adolescent sexual offenders and general population juvenile delinquents in Michigan. The sample sizes were adequate but not large, especially for the use of a multivariate regression analysis seeking interaction effects. This may limit some of the findings Finally, the early offender group might have included youth who were concerned about possible reporting of results who lied about their behavior.

\section{Conclusions}

In conclusion, many adolescent sexual offenders reported having been children with sexual behavior problems. It would appear that focusing on those children when the behavior is first recognized is a justifiable expense and may be critical to the prevention of adolescent sexual offending which is responsible for up to $40 \%$ of the reported sexual offenses in North America (Abel et al., 1993). The role of traumatization in sexual offending needs more examination, as significant differences were found in children with sexual behavior problems in terms of trauma and aggressivity (Burton et al., 1997) and, similarly, in this study between adolescent groups. Further tests of theory, treatment models, sexual offender developmental 
processes and progression, evaluation of intensive work with children and their families, development of appropriate funding for treatment and research, and the development of policy aimed at treatment, are all indicated.

\section{REFERENCES}

Abel, G., Osborn, C., \& Twigg, D. (1993). Sexual assault through the life span: Adult offenders with childhood histories. In H. Barbaree, W. Marshall, \& S. Hudson (Eds.), The juvenile sex offender. New York: Guilford Press.

Araji, S. K. (1997) Sexually aggressive children: Coming to understand them. Thousand Oaks, CA: Sage.

Bandura, A., \& Walters, R. (1963). Social learning and personality development.

Becker, J., Cunningham-Rathner, J., \& Kaplan, M. S. (1986). Adolescent sexual offenders: Demographics, criminal and sexual histories, and recommendations for reducing future offenses. Journal of Interpersonal Violence, 1, 431-445.

Burgess, A., Hartman, C., McCormack, A., \& Grant, C. (1995). Child victim to juvenile victimizer: Treatment implications. International Journal of Family Psychiatry, 9, 403-416.

Burton, D. (1996). Cognitive factors in sexually aggressive children. Unpublished doctoral dissertation, University of Washington, Seattle.

Burton, D. (1999). An examination of social cognitive theory with differences among sexually aggressive, physically aggressive and nonaggressive children in state care Violence and Victims (in press).

Burton, D., Nesmith, A., \& Badten, L. (1997). Clinician's views of sexually aggressive children: A theoretical exploration. Child Abuse and Neglect, 21, 157-170.

Burton, D., Freeman-Longo, R., \& Fiske, J. (1999). 1996 Nationwide survey of treatment programs \& models serving abuse-reactive children, adolescent and adult sex offenders. Burlington, VT: Safer Society Press (in press).

Cunningham, C., \& MacFarlane, K. (1991). When children molest children. Orwell, VT: Safer Society.

Davis, G., \& Leitenberg, H. (1987). Adolescent sex offenders. Psychological Bulletin, 101, 417-427.

Doumas, D., Margolin, G., \& John, R. S. The intergenerational transmission of aggression across three generations. Journal of Family Violence, 9, 157-175.

Freeman-Longo, R., \& Blanchard, G. (1997). Sexual abuse in America: Epidemic of the 21st century. Burlington, VT: Safer Society.

Freeman-Longo, R., Bird, S., Stevenson, W., \& Fiske, J. (1995). 1994 Nationwide survey of treatment programs \& models serving abuse-reactive children and adolescent \& adult sex offenders. Burlington, VT: Safer Society.

Friedrich, W., \& Luecke, W. (1988). Young school-age sexually aggressive children. Professional Psychology: Research and Practice, 19, 155-164.

Friedrich, W., Grambsch, P., Damon, L., Hewitt, S., Koverola, C., Lang, R., Wolfe, V., \& Broughton, D. (1991). Normative sexual behavior in children. Pediatrics, 88, 456-464.

Garland, R., \& Dougher, M. (1990). The abused/abuser hypothesis of child sexual abuse: A critical review of theory and research. In J. Fierman (Ed.), Pedophilia: Biosocial dimensions (pp. 488509). New York: Springer-Verlag.

Gil, E., \& Johnson, T. (1994). Sexualized children: Assessment and treatment of sexualized children and children who molest. Rockville, MD: Launch.

Howells, K., \& Cook, M. (Eds.) (1981). Adult sexual interest in children: Considerations relevant to theories of aetiology (Vol. 22). London: Academic Press.

Hunter, J. (1994). Etiology of adolescent sexual offending. Paper presented at the 13th Annual Research and Treatment Conference, The Association for the Treatment of Sexual Abusers, San Francisco, Nov.

Johnson, T. (1988). Child perpetrators-Children who molest other children: Preliminary findings. Child Abuse and Neglect, 12, 219-229. 
Johnson, T. (1989). Female child perpetrators: Children who molest other children. Child Abuse and Neglect, 13, 571-584.

Johnson, T., \& Berry, C. (1989). Children who molest: A treatment program. Journal of Interpersonal Violence, 4, 185-203.

Okami, P. (1992). Child perpetrators of sexual abuse: The emergence of a problematic deviant category. Journal of Sex Research, 29, 109-130.

Pierce, L., \& Pierce, R. (1990). Adolescent/sibling incest perpetrators. The incest perpetrator: A family member no one wants to treat. In A. Horton, B. Johnson, L. Roundy, \& D. William (Eds.). Newbury Park, CA: Sage.

Pithers, B., \& Gray, A. (1997). Cluster analysis of children with sexual behavior problems. Paper presented at the 16th Annual Research and Treatment Conference of the Association for the Treatment of Sexual Abusers, Washington, DC, Oct.

Pithers, W., Gray, A., Busconi, A., \& Houchens, P. (1998). Caregivers of children with sexual behavior problems: Psychological and familial functioning. Child Abuse and Neglect, 22, 129-141.

Ray, J., \& English, D. (1995). Comparison of female and male children with sexual behavior problems. Journal of Youth \& Adolescence, 24, 439-451.

Roche, A., Wellens, R., Attie, K., \& Siervogel, R. (1995). The timing of sexual maturation in a group of US youths. Journal of Pediatric Endocrinology and Metabolism, 8, 8-11.

Ryan, S., Rodriguez, J., Anderson, R., \& Foy, D. (1992). Psychometric analysis of the sexual abuse exposure questionnaire (SAEQ). Paper presented at the American Psychological Association, Washington, DC.

Vizard, E., Monck, E., \& Misch, P. (1995). Child and adolescent sex abuse perpetrators: A review of the research literature. Journal of Child Psychological Psychiatry, 36, 731-756.

Waggoner, R., \& Boyd, D., Jr., (1941). Juvenile aberrant sexual behavior. The American Journal of Orthopsychiatry, 11, 275-291.

Widom, C. (1989). Does violence beget violence? A critical examination of the literature. Psychological Bulletin, 106, 3-28. 